\title{
Nutritional status determines apparent assimilative capacity and functional response of marine predatory fish
}

Andersen, Niels Gerner; Neuenfeldt, Stefan; Bogstad, Bjarte; Andersen, Ken Haste; Beyer, Jan Erik

Published in:

ICES Journal of Marine Science

Link to article, DOI:

10.1093/icesjms/fsab197

Publication date:

2021

Document Version

Other version

Link back to DTU Orbit

Citation (APA):

Andersen, N. G., Neuenfeldt, S., Bogstad, B., Andersen, K. H., \& Beyer, J. E. (2021). Nutritional status determines apparent assimilative capacity and functional response of marine predatory fish. ICES Journal of Marine Science, 78(10), 3615-3624. [fsab197]. https://doi.org/10.1093/icesjms/fsab197

\section{General rights}

Copyright and moral rights for the publications made accessible in the public portal are retained by the authors and/or other copyright owners and it is a condition of accessing publications that users recognise and abide by the legal requirements associated with these rights.

- Users may download and print one copy of any publication from the public portal for the purpose of private study or research.

- You may not further distribute the material or use it for any profit-making activity or commercial gain

- You may freely distribute the URL identifying the publication in the public portal 


\title{
Supplementary material
}

for

\section{Nutritional status determines apparent assimilative capacity and functional response of marine predatory fish}

\author{
Niels G. Andersen ${ }^{1}$, Stefan Neuenfeldt ${ }^{1}$, Bjarte Bogstad ${ }^{2}$, Ken H. Andersen ${ }^{1}$, Jan Erik Beyer ${ }^{1}$ \\ ${ }^{1}$ Technical University of Denmark, National Institute of Aquatic Resources (DTU-Aqua), \\ Building 202, Kgs. Lyngby 2800, Denmark \\ ${ }^{2}$ Institute of Marine Research, P.O. Box 1870 Nordnes, Bergen 5817, Norway
}

\section{Contents}

Appendix S1: Estimating and testing stomach and GER allometry: deriving a general predictor of GER across predators . . . . . . . . . . . . . . . 2

Appendix S2: Estimation of $C_{\mathrm{MAX}}, S_{\max }$ and factorial hyperphagic scope $\ldots \ldots .14$

Appendix S3: Description of stomach content data and estimation of maximum stomach content mass $S_{\mathrm{MAX}}$ and its allometry . . . . . . . . . . . . . . 18

Appendix S4: Maximum food consumption rate and stomach filling of well-fed and prestarved Atlantic cod (Gadus morhua) in laboratory experiments . . . . . . . . . 


\section{Appendix S1}

\section{Estimating and testing stomach and GER allometry: deriving a general predictor of GER across predators}

The cylinder model of gastric evacuation rate (GER) is at present the only model that is able to accurately predict GER of current stomach content mass irrespectively of prey composition and temporal feeding pattern (Andersen, 2012). Using this model in the present study, we derive a general GER allometry and provide a common inter-specific value of the basic rate parameter that significantly facilitate the general use of the model for predatory fish because just stomach length relative to the total body length needs to be known. The mechanistic principles of the model further allow us to calculate a proxy for the maximum volume capacity $S_{\mathrm{MAX}}$ of any predatory fish if the mass and length of the stomach are known.

In this supplement, we examine the assumptions connected to the derivation of the general GER allometry, corroborate the derived allometry and estimate a common inter-predator

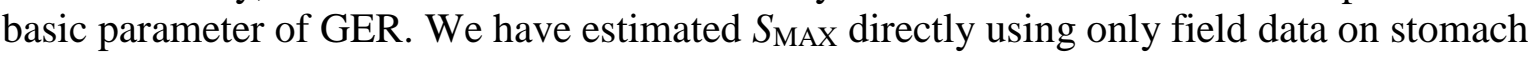
content of sampled cod and whiting. We therefore define a useful proxy for $S_{\text {MAX }}$ to connect assimilative capacity with foraging strategy for a larger number of predator species.

\section{Testing the assumptions for the derivation of general GER allometry}

We examined the assumptions about isometric stomach growth and the constant ratio $\lambda$ of stomach length $l$ to total body length $L$ for a variety of marine species. Individuals of whiting (Merlangius merlangus), Atlantic cod (Gadus morhua), saithe (Pollachius virens), grey gurnard (Eutrigla gurnardus), and haddock (Melanogrammus aeglefinus) were sampled and processed on board the Danish research vessel 'Dana' during the International Bottom trawl Survey in the North Sea (www.ices.dk) in August 2011 as well as a commercial trawler later the same year in the Danish Skagerrak. Live turbot (Psetta maxima) were acquired from a local gillnetter in Hirtshals, Denmark, and processed on land. The total body length $L$ was measured, the body cavity opened, and the stomach length $l$ measured (to nearest $\mathrm{mm}$ below) from septum transversum in front of the body cavity to the caudal end of the stomach. The stomach was then excised, cut open longitudinally, emptied, flushed with isotonic salt water, dabbed with moistened paper towel to get rid of surplus water, wrapped in aluminium-foil on board the ship, frozen, and finally weighed on land. The data are available in the accompanying Excel files.

Using nonlinear regression of a power function with free exponent and intercept, we could not for any of the predators reject a linear relationship between $l$ and $L$ with the regression line going through origin. The mean of the individual values of $\lambda=l L^{-1}$ was therefore estimated by species and compared for significant difference using ANOVA followed by Tuckey HSD Post-Hoc Test. Significance was accepted for $\mathrm{P}<0.05$. The low values obtained from whiting and saithe differed from the other species, whereas cod, turbot and grey gurnard showed similar values like did cod, grey gurnard and haddock (Table S1.1). Data together with the fit of the linear relationship by predator species are shown in Figure S1.1. 
We examined the stomach growth for isometry with data on stomach mass $w$ (g) and stomach length $l(\mathrm{~cm})$ for each predator by nonlinear regression using the simple power function $w=a$ $l^{b}$. The exponent $b$ was not significantly different from the isometric value of 3 for any of the predators. The estimates of the prefactor $a$ in the isometric relationship are provided in Table S1.1. Data together with the fit of the isometric power function by predator species are shown in Figure S1.2.

Table S1.1. Estimate by predator species of the ratio $\lambda$ of stomach length $l$ to total predator length $L$, the prefactor $a$ relating stomach mass $w(\mathrm{~g})$ to $l(\mathrm{~cm})$ by $w=a l^{3}$, and the proxy $a \lambda$ for $S_{\mathrm{MAX}}$. Values with different superscript letters are significantly different $(\mathrm{P}<0.05)$

\begin{tabular}{|c|c|c|c|c|c|c|c|c|}
\hline \multirow[b]{2}{*}{ Predator } & \multirow{2}{*}{$\begin{array}{c}L \text { range } \\
(\mathrm{cm})\end{array}$} & \multicolumn{2}{|c|}{$\lambda$} & \multicolumn{2}{|c|}{$a\left(\times 10^{-3}\right)$} & \multicolumn{2}{|c|}{$a \lambda\left(\times 10^{-3}\right)$} & \multirow[b]{2}{*}{$n$} \\
\hline & & Estimate & $95 \% \mathrm{CI}$ & Estimate & $95 \% \mathrm{CI}$ & Estimate & $95 \% \mathrm{CI}$ & \\
\hline Whiting & $18-46$ & $0.233^{\mathrm{a}}$ & \pm 0.002 & $5.99^{\mathrm{a}}$ & \pm 0.16 & $1.39^{\mathrm{a}}$ & \pm 0.04 & 73 \\
\hline Saithe & $42-81$ & $0.244^{b}$ & \pm 0.003 & $6.34^{\mathrm{a}}$ & \pm 0.14 & $1.55^{\mathrm{b}}$ & \pm 0.04 & 57 \\
\hline Turbot & $18-53$ & $0.264^{\mathrm{c}}$ & \pm 0.003 & $7.95^{b}$ & \pm 0.19 & $2.10^{\mathrm{c}}$ & \pm 0.06 & 61 \\
\hline Grey gurnard & $15-42$ & $0.259^{\mathrm{c}, \mathrm{d}}$ & \pm 0.002 & $7.40^{\mathrm{c}}$ & \pm 0.18 & $1.91^{\mathrm{d}}$ & \pm 0.05 & 88 \\
\hline Haddock & $21-64$ & $0.257^{\mathrm{d}}$ & \pm 0.003 & $7.60^{\mathrm{b}, \mathrm{c}}$ & \pm 0.16 & $1.96^{\mathrm{d}}$ & \pm 0.05 & 71 \\
\hline Atlantic cod & $21-93$ & $0.262^{\mathrm{c}, \mathrm{d}}$ & \pm 0.002 & $9.23^{\mathrm{d}}$ & \pm 0.28 & $2.41^{\mathrm{e}}$ & \pm 0.07 & 64 \\
\hline
\end{tabular}

\section{Proxy for maximum volume capacity $S_{\text {MAX }}$ of the stomachs}

The maximum stomach dilation depends on the number and size of the longitudinal folds of the stomach wall and associated structures that allow the mucosa surface to unfold and expand in pace with mass $S$ of total stomach contents to contribute to the digestive processes in accordance with the cylinder GER model. The $l$-specific stomach mass described by the prefactor $a=w l^{-3}$ (Table S1.1) thus indicates how much the stomach is able to expand; i.e., the circumference and consequently the maximum lumen of a cross section of the stomach cylinder. The low values of $a$ obtained from whiting and saithe were similar, and significantly different from the other predators. The high value for cod was different from all other species, whereas turbot and haddock provided similar intermediate values as did grey gurnard and haddock. If the relative stomach length $\lambda=l L^{-1}$ was the same for all predators, $a$ could serve directly as a proxy for $S_{\text {MAX }}$. However, species-specific $\lambda$ values imply that instead $a \lambda$ must be used to serve as a proxy for the total maximum volume capacity of the stomach for a given $L$. The $l$-specific stomach mass $a$ times $\lambda$ corrects for the inter-species difference in $\lambda$. It can therefore be used as a proxy for each predator to connect $S_{\text {MAX }}$ and eventually $C_{\text {MAX }}$ with foraging strategy. All estimates of $a \lambda$ with the exception of those for grey gurnard and haddock were different (Table S1.1). The estimates can however be arranged in three distinct groups with cod holding the highest value, turbot, grey gurnard and haddock attaining medium values, and saithe and whiting providing the lowest ones.

\section{Empirical evidence of the derived allometry of GER}

A number of values of the length scaling exponent ranging from 1.3 to 1.4 was obtained from GER data on predators in the literature and corroborate the derived interval $5 / 4-3 / 2$ (haddock, Jones, 1974; whiting, saithe, Andersen, 2001; cod, Andersen, 2012; turbot, Krog and 
Andersen, 2009; brook trout (Salvelinus fontinalis), Khan et al., 2016; whiting, Ross et al., 2018). Lower values have been reported as well. The latter are mostly obtained from data that include different meal sizes using an exponential GER function (i.e., $\frac{\mathrm{d} S_{t}}{\mathrm{~d} t}=-\rho S_{t}$, where $S_{t}$ is the current stomach content mass and $\rho$ the rate parameter) or different prey sizes increasing with predator size without accounting for prey energy density (e.g. dos Santos and Jobling, 1995; Koed, 2001). The exponential overestimates GER of large meals (Temming and Andersen, 1994), and prey energy density usually increases with prey size, which depresses GER (Jobling, 1986). Both of these circumstances depress the estimated effect of predator size on GER (Andersen, 2012). It should be mentioned that Temming and Herrmann (2003) obtained lower estimates of $c .0 .90$ of the length exponent from extensive datasets on cod. Their analyses of these datasets were however rather convoluted due to the complex data structure, which might have caused bias. We therefore disregard this result here.

To attain a common scaling in a consistent way, we re-estimated the intra-specific effect of body length on GER from data on whiting and saithe (Andersen, 2001) using the nonlinear regression procedure described in Krog and Andersen (2009) and Andersen (2012) for turbot and cod. Kahn et al. (2016) used this procedure as well on brook trout like we did on grey gurnard (unpublished data, N.G. Andersen, see data in the accompanying Excel files). The estimates of the scaling power were not significantly different (ANOVA, P>0.05) (Table S1.2), and we used a common value of 1.35 for all species in the following.

Table S1.2. Estimates of the exponent $k$ relating gastric evacuation rate (GER) to total predator length $L$ (cm) by $\frac{\mathrm{d} S_{t}}{\mathrm{~d} t}=-\rho_{L} L^{k} \sqrt{S_{t}}$, where $S_{t}$ is the current stomach content mass $(\mathrm{g})$ and $\rho_{L}$ the rate parameter. The methodology by Andersen (2012) was used for all estimations. None of the estimates of $k$ were significantly different $(\mathrm{P}>0.05)$

\begin{tabular}{|c|c|c|c|c|c|}
\hline \multirow[b]{2}{*}{ Predator } & \multirow[b]{2}{*}{ Data source } & \multicolumn{2}{|c|}{$k$} & \multirow[b]{2}{*}{$r^{2}$} & \multirow[b]{2}{*}{$n$} \\
\hline & & Estimate & $95 \% \mathrm{CI}$ & & \\
\hline Whiting (Merlangius merlangus) & Andersen (2001) & $* 1.35$ & \pm 0.14 & 0.962 & 97 \\
\hline Atlantic cod (Gadus morhua) & Andersen (2012) & 1.31 & \pm 0.09 & 0.961 & 109 \\
\hline Saithe (Pollachius virens) & Andersen (2001) & $* 1.38$ & \pm 0.10 & 0.978 & 129 \\
\hline Turbot (Psetta maxima) & Krog and Andersen (2009) & 1.41 & \pm 0.25 & 0.907 & 77 \\
\hline Brook trout (Salvelinus fontinalis) & Kahn et al. (2016) & 1.31 & \pm 0.09 & 0.972 & 90 \\
\hline Grey gurnard (Eutrigla gurnardus) & Andersen (unpubl. data) & $* 1.33$ & \pm 0.14 & 0.967 & 74 \\
\hline
\end{tabular}

*Estimated from unpublished data (E. gurnardus) or re-estimated from already published studies (all these data are available in the accompanying Excel files) 

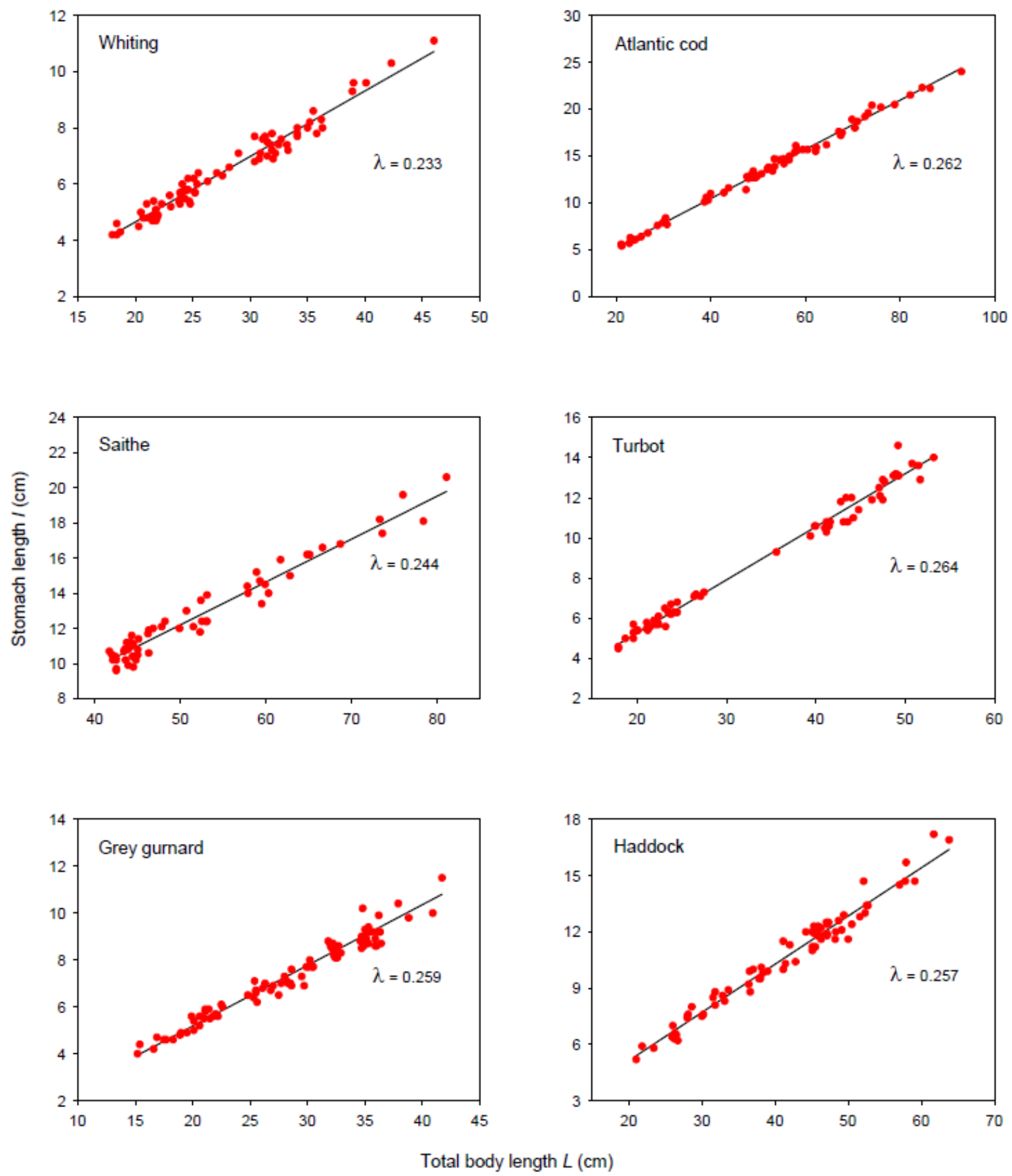

Figure S1.1. Data on the relationship between stomach length $l$ and total body length $L$ together with the curve described by the linear function $l=\lambda L$ for each of the examined predators. Confidence limits of $\lambda$ and results from test of difference between predators are reported in Table S.1.1. 

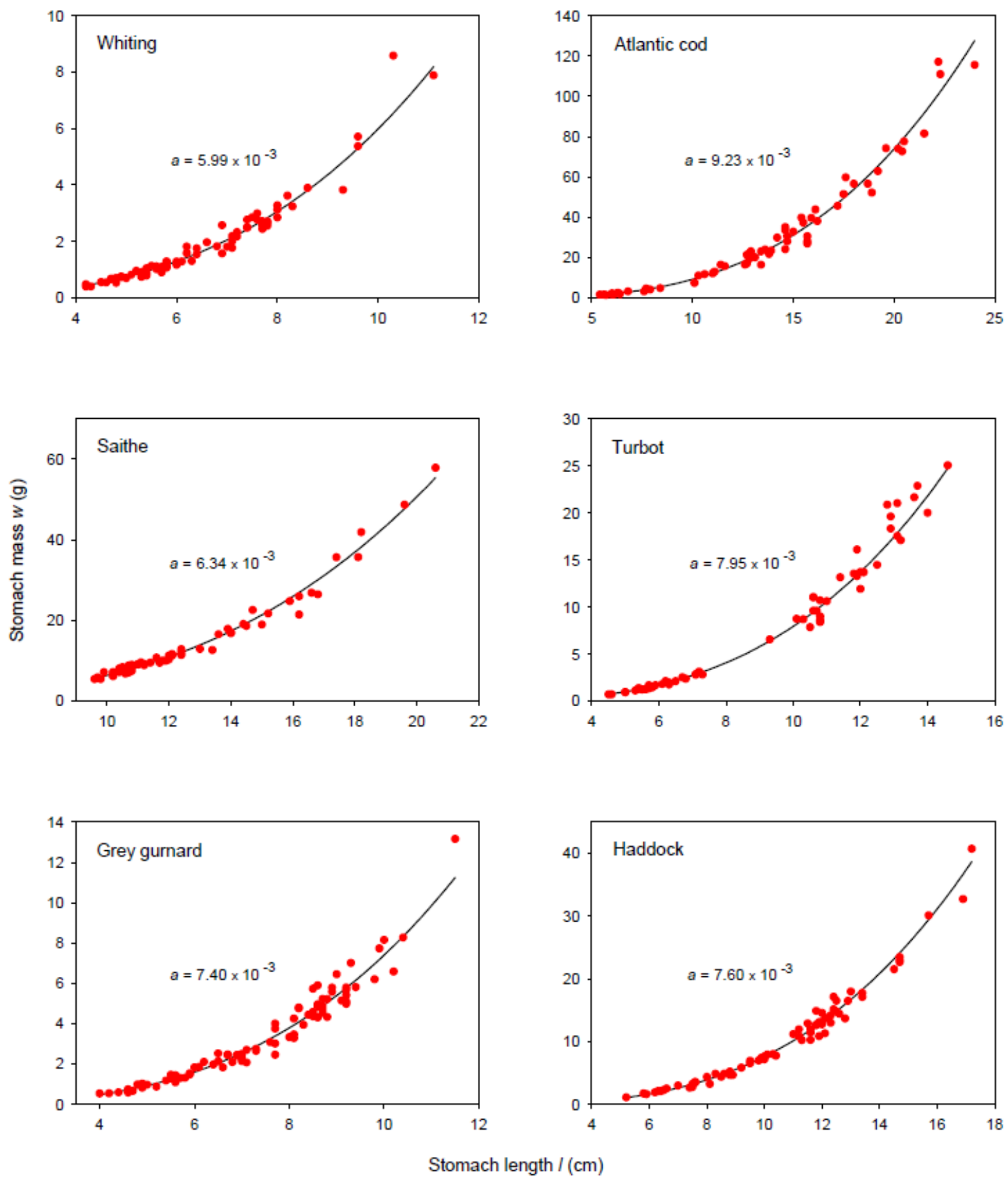

Figure S1.2. Data on the relationship between stomach length $l$ and mass $w$ together with the curve described by the isometric function $w=a l^{3}$ for each of the examined predators. Confidence limits of $a$ and results from test of difference between predators are reported in Table S.1.1. 


\section{Generic and mechanistic GER forecasting: the common inter-predator specific predictor variable}

We assume that the digestive capacity of the stomach per unit of mucosa surface area is optimized to reduce costs of development and maintenance as well as occupation of body space. In accordance with the cylinder model, $l$ rather than $L$ should then be the predictor of GER across predator species. We used GER data from a number of predator species fed lesser sandeel (Ammodytes tobianus) to examine whether the stomach length $l$ actually is the common inter-predator specific predictor variable.

First, expanding the GER rate parameter $\rho$ to include the effects of predator length $L(\mathrm{~cm})$, temperature $T\left({ }^{\circ} \mathrm{C}\right)$, and prey energy density $E\left(\mathrm{~kJ} \mathrm{~g}^{-1}\right)$ we describe GER in accordance with the cylinder model by

$$
\frac{\mathrm{d} S_{t}}{\mathrm{~d} t}=-\rho_{0} L^{1.35} e^{0.080 T} E^{-0.85} \sqrt{S_{t}}\left(\mathrm{~g} \mathrm{~h}^{-1}\right)
$$

where $\rho_{0}$ represents the predator-specific parameter for sandeel prey. The temperature coefficient is a generally accepted value for enzymatic processes (Schmidt-Nielsen, 1983) and is representative of GER for a suite of predatory fish as well (Andersen, 2012). It should however be noted that other constraints on GER may come into play at more extreme temperatures within a species' temperature range (see later). The exponent of $E$ was estimated from different gadoid predators (Andersen, 2001, 2012), and the value implies that the fish are able to adjust GER of energy almost independently of prey energy density (total independence requires a value of -1$)$. Using evacuation data from the above-mentioned five marine predators fed sandeel (Ammodytes tobianus) (see the accompanying Excel files), we compare the estimated values of $\rho_{0}$ (Table S1.3). Integrating GER in Equation (S1.1) from time 0 of food intake to time $t$ of recovery of the stomach contents, we calculate a value of

$$
\rho_{0}=2\left(\sqrt{S_{0}}-\sqrt{S_{t}}\right)\left(L^{1.35} e^{0.080 T} E^{-0.85} t\right)^{-1}
$$

from evacuation data on each predator individual as the outcome of a normally distributed variable (Andersen, 2012). The predator-specific estimate of $\rho_{0}$ is then the mean of the values obtained from all individuals of that predator species. The estimates are compared statistically by ANOVA and in the case of significance followed by Tuckey HSD Post-Hoc Test for species differences. Significance is accepted for $\mathrm{P}<0.05$.

Second, we follow the same procedure with $L$ replaced by stomach length $l$ using the relationship

$$
\frac{\mathrm{d} S_{t}}{\mathrm{~d} t}=-\rho_{0}(\lambda L)^{1.35} e^{0.08 T} E^{-0.85} \sqrt{S_{t}}
$$

and expecting that $\rho_{0}$ should be similar across predators if mucosa performance is optimized.

Using $L$, the estimates of $\rho_{0}$ were significantly different. Replacing $L$ by predator-specific stomach length $l$ (using $\lambda L$ ) provided similar values of $\rho_{0}$ for all the predators, which corroborates the usefulness of the common, interspecific value of the evacuation rate parameter for piscivorous fish if their stomach lengths are known (Table S1.3). Data together with the evacuation curve by predator species, predicted using the common value of the stomach length-based $\rho_{0}$, are shown in Figures S1.3-S1.5. 
Table S1.3. Estimates of the predator-specific rate parameter $\rho_{0}$ obtained from data on gastric evacuation of sandeel prey using $\frac{\mathrm{d} S_{t}}{\mathrm{~d} t}=-\rho_{0} L^{1.35} e^{0.080 T} E^{-0.85} \sqrt{S_{t}}$ or $\frac{\mathrm{d} S_{t}}{\mathrm{~d} t}=-\rho_{0}(\lambda L)^{1.35} e^{0.080 T} E^{-0.85} \sqrt{S_{t}}\left(\mathrm{~g} \mathrm{~h}^{-1}\right)$, where $L$ is total predator length $(\mathrm{cm}), \lambda$ relative stomach length, $T$ temperature $\left({ }^{\circ} \mathrm{C}\right), E$ prey energy density $\left(\mathrm{kJ} \mathrm{g}^{-1}\right)$ and $S_{t}$ current stomach content mass $(\mathrm{g})$. Values with different superscript letters are significantly different $(\mathrm{P}<0.05)$. Data sources are listed in Table S1.2, and the data used here are available in the accompanying Excel files.

\begin{tabular}{lccccccr}
\hline & \multicolumn{2}{c}{$L$-based $\rho_{0}\left(\times 10^{-3}\right)$} & & \multicolumn{2}{c}{$l$-based $\rho_{0}\left(\times 10^{-2}\right)$} & \\
\cline { 2 - 3 } Predator & Estimate & $95 \%$ CI & & Estimate & $95 \%$ CI & $n$ \\
\hline Whiting (Merlangius merlangus) & $1.65^{\mathrm{a}}$ & \pm 0.04 & & $1.18^{\mathrm{a}}$ & \pm 0.03 & 149 \\
Atlantic cod (Gadus morhua) & $1.97^{\mathrm{b}}$ & \pm 0.05 & & $1.20^{\mathrm{a}}$ & \pm 0.03 & 145 \\
Saithe (Pollachius virens) & $1.76^{\mathrm{a}, \mathrm{c}}$ & \pm 0.09 & & $1.18^{\mathrm{a}}$ & \pm 0.06 & 21 \\
Turbot (Psetta maxima) & $1.93^{\mathrm{b}, \mathrm{c}}$ & \pm 0.18 & & $1.17^{\mathrm{a}}$ & \pm 0.11 & 19 \\
Grey gurnard (Eutrigla gurnardus) & $1.99^{\mathrm{b}}$ & \pm 0.16 & & $1.24^{\mathrm{a}}$ & \pm 0.09 & 19 \\
All predators; common estimate & - & - & & 1.19 & \pm 0.02 & 353 \\
\hline
\end{tabular}

The common estimate of $\rho_{0}$ applies to predators that eat fish prey, which vary only a little in their resistance to the digestive processes (e.g. Andersen, 2012). The resistance of some invertebrate prey may however differ significantly, which should be considered if they comprise a substantial part of the predator's diet. Crustaceans constitute the most important invertebrate prey for most marine piscine predators. Values of $\rho_{0}$ for the different groups of crustaceans have been estimated (Andersen et al., 2016) and can be used in the same way to estimate GER by the cylinder model.

The effect of temperature on GER described by the exponential with a coefficient of 0.08 probably does not apply for most fish experiencing extreme temperatures. An optimum temperature followed by a decline close to the upper tolerance limit has been reported for cod as well as a number of other species (e.g. Brett and Higgs, 1970; Tyler, 1970; Sweka et al., 2004; Bernreuther et al., 2009, Andersen 2012). A likely explanation is constraints and eventual collapse in the cardiovascular system, probably because of a mismatch in the heart between oxygen supply and demand (Lannig et al., 2004; Farrell et al., 2009). Using the exponential, dos Santos and Jobling $(1991,1992,1995)$ further obtained values of the temperature coefficient between 0.11 and 0.13 in the temperature interval $1-14^{\circ} \mathrm{C}$. Using a segment of dos Santos and Jobling's data on temperatures in the interval $1-6{ }^{\circ} \mathrm{C}$, Salvanes et al. (1995) estimated an even higher estimate of 0.23. Low temperatures thus also seem to impose a constraint upon GER (Figure S1.6). The mechanism behind has not been examined for fish. However, aquatic invertebrates and insects fail to maintain ion and water balance at low temperature (MacMillan, 2019), and this may as well be the case for fish. 


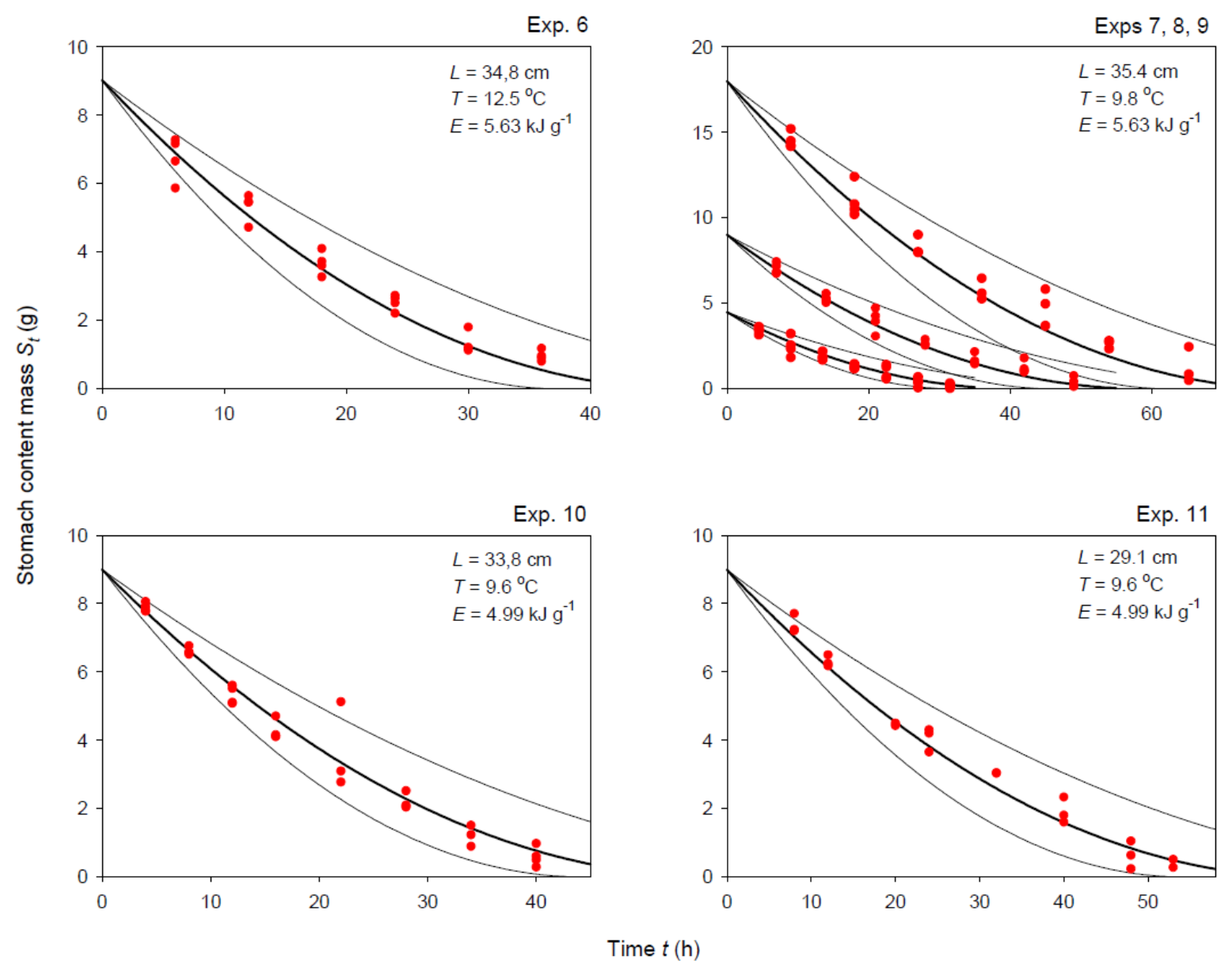

Figure S1.3. Data on remaining stomach content mass $S_{t}$ at postprandial time $t$ in whiting fed meals of sandeel. The predicted gastric evacuation curves are provided using the integrated version of Equation (S1.3) with the common estimate $0.0119 \pm 2$ S.D. of $l$-based $\rho_{0}$ obtained from data on all predators, and the whiting-specific estimate 0.233 of $\lambda$. Predator length $L$, temperature $T$ and prey energy density $E$ are provided as well. Experiment Nos refer to the accompanying Excel files. 
Exps 1,2

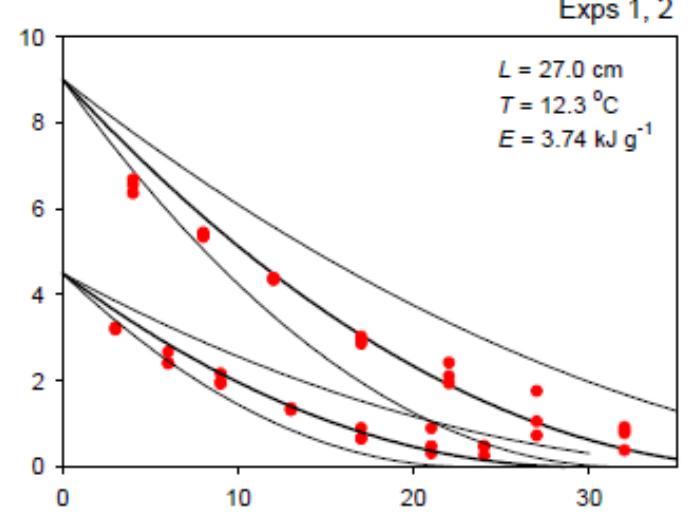

Exp. 4
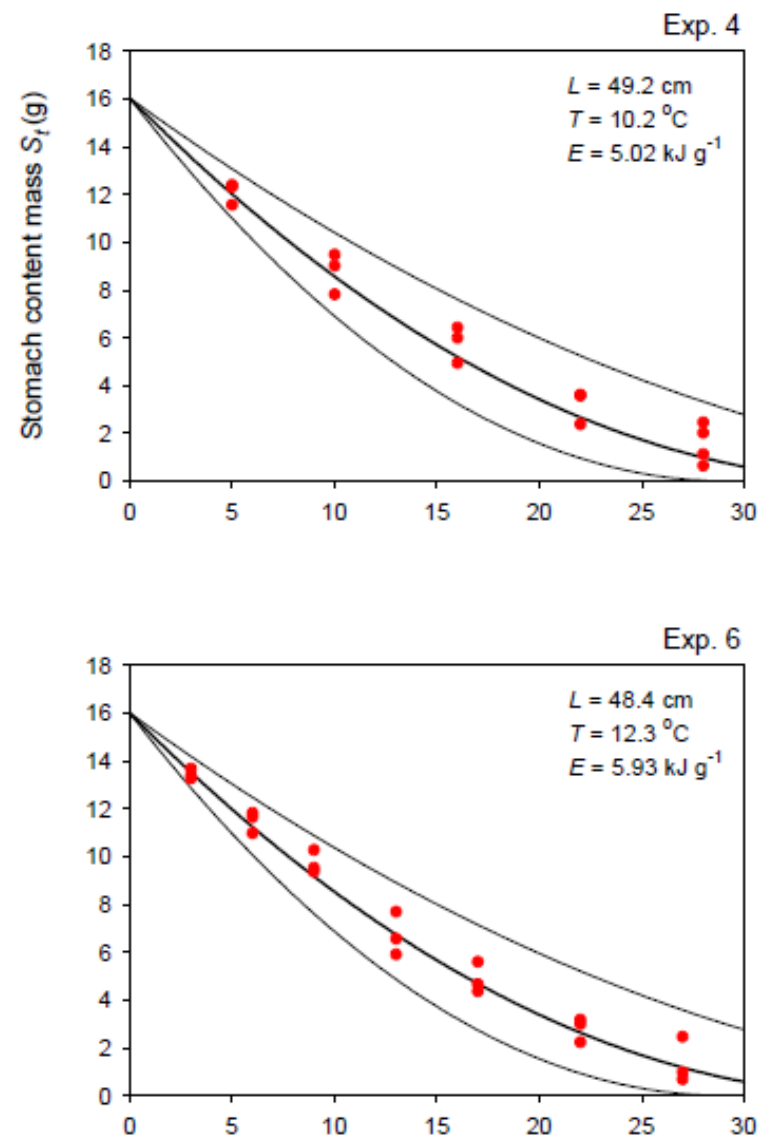

Exp. 3

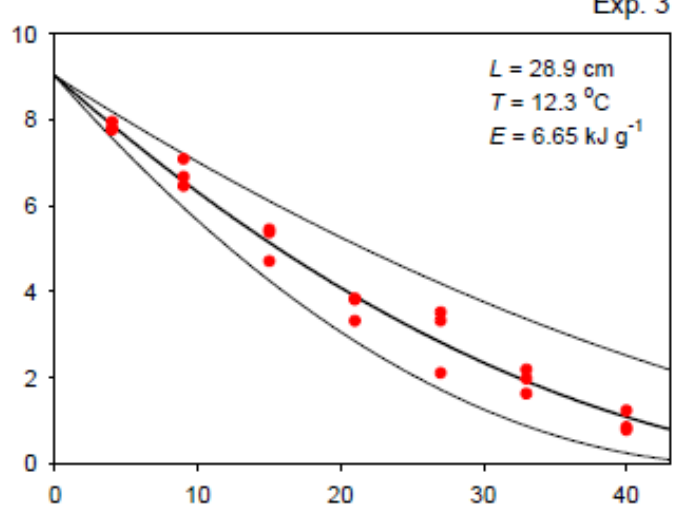

Exp. 5
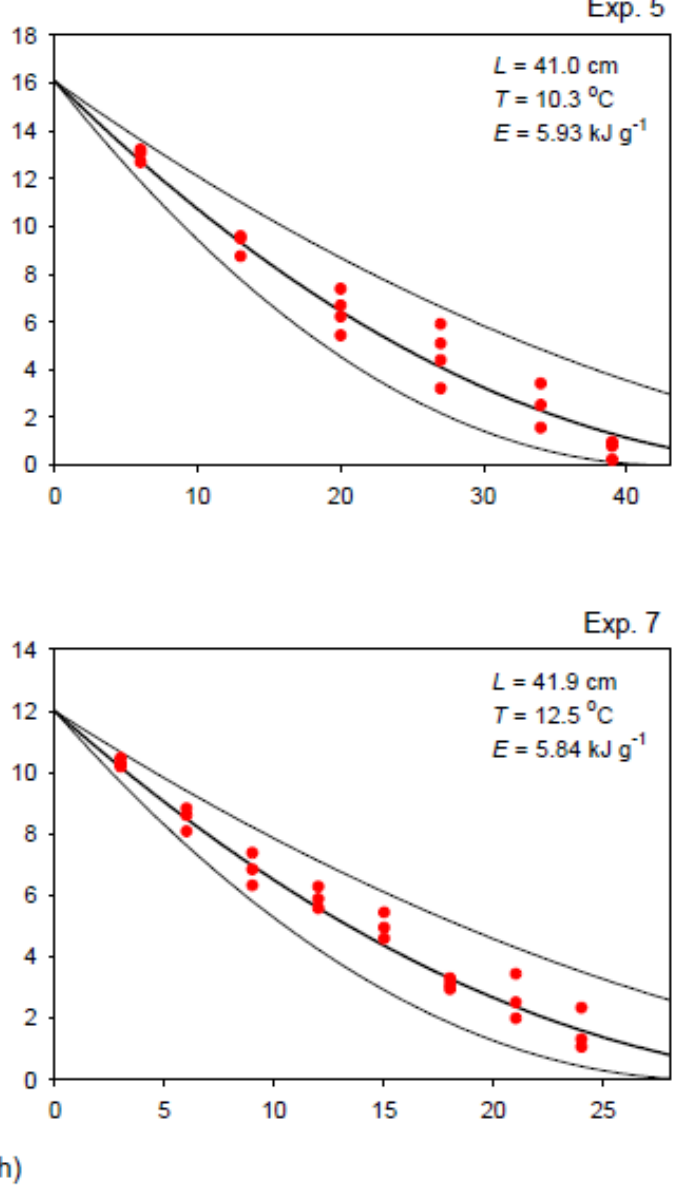

Figure S1.4. Data on remaining stomach content mass $S_{t}$ at postprandial time $t$ in Atlantic cod fed meals of sandeel. The predicted gastric evacuation curves are provided using the integrated version of Equation (S1.3) with the common estimate $0.0119 \pm 2$ S.D. of $l$-based $\rho_{0}$ obtained from data on all predators, and the cod-specific estimate 0.262 of $\lambda$. Predator length $L$, temperature $T$ and prey energy density $E$ are provided as well. Experiment Nos refer to the accompanying Excel files. 


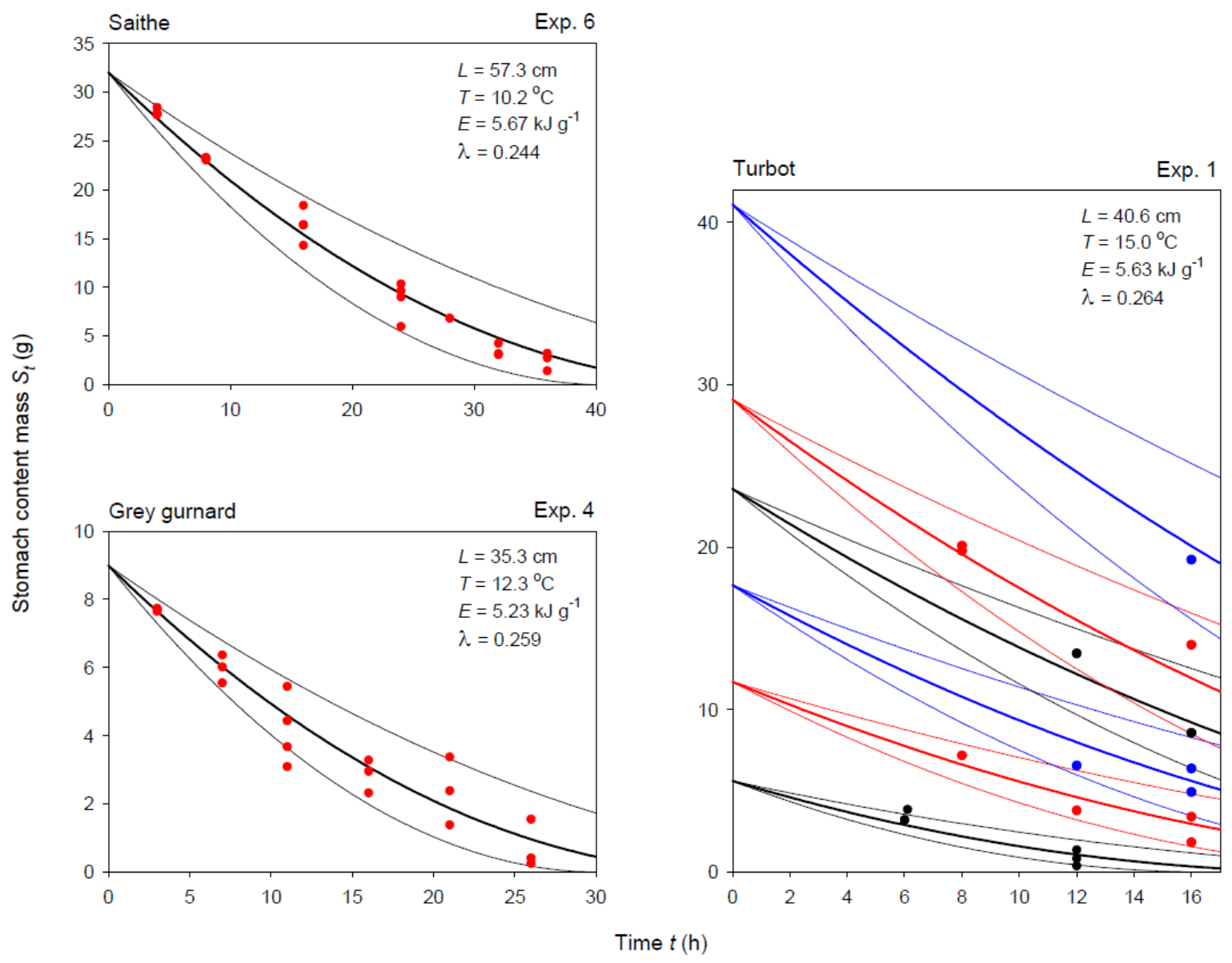

Figure S1.5. Data on remaining stomach content mass $S_{t}$ at postprandial time $t$ in other predatory fishes fed meals of sandeel. The predicted gastric evacuation curves are provided using the integrated version of Equation (S1.3) with the common estimate $0.0119 \pm 2$ S.D. of $l$-based $\rho_{0}$ obtained from data on all predators, and the predator-specific estimates of $\lambda$. Predator length $L$, temperature $T$ and prey energy density $E$ are provided as well. Experiment Nos refer to the accompanying Excel files.

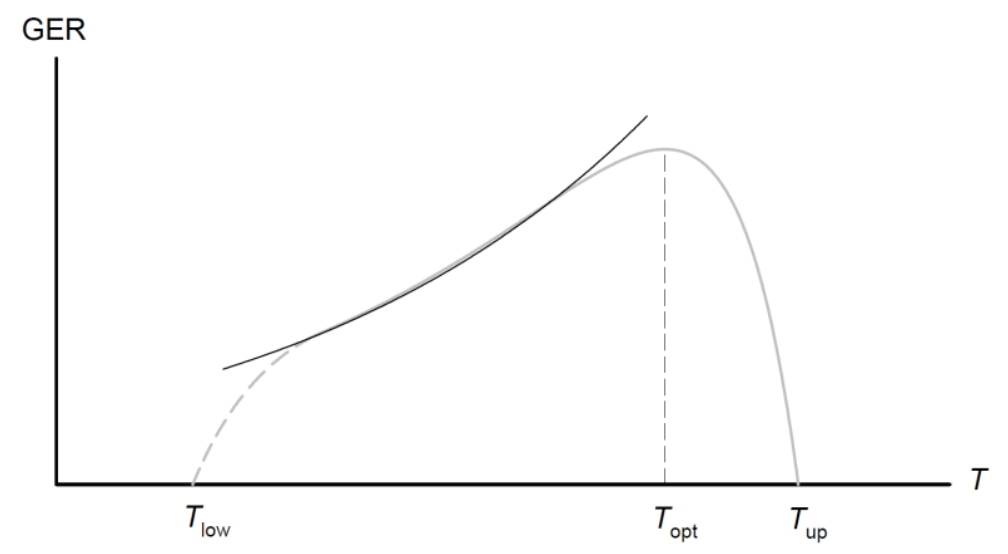

Figure S1.6. The influence of temperature $T$ on gastric evacuation rate (GER) according to a simple exponential ( - ) and an optimum temperature $T_{\text {opt }}$ function $(-) . T_{\text {low }}$ and $T_{\text {up }}$ indicate the lower and upper temperature tolerance limits of the predator. The dashed part of the grey line indicates the likely stronger effect of temperature close to the lower tolerance limit that is not described by the optimum temperature function. 


\section{References}

Andersen, N. G. 2001. A gastric evacuation model for three predatory gadoids and implications of using pooled field data of stomach contents to estimate food rations. Journal of Fish Biology, 59: 1198-1217.

Andersen, N. G. 2012. Influences of potential predictor variables on gastric evacuation in Atlantic cod Gadus morhua feeding on fish prey: parameterization of a generic model. Journal of Fish Biology, 80: 595-612.

Andersen, N. G., Chabot, D., and Couturier, C. S. 2016. Modelling gastric evacuation in gadoids feeding on crustaceans. Journal of Fish Biology, 88: 1886-1903.

Bernreuther, M., Temming, A., and Herrmann J.-P. 2009. Effect of temperature on the gastric evacuation in sprat Sprattus sprattus. Journal of Fish Biology, 75: 1525-1541.

Brett, J. R., and Higgs, D. A. 1970. Effect of temperature on the rate of gastric digestion in fingerling sockeye salmon. Journal of the Fisheries Research Board of Canada, 27: 17671778.

dos Santos, J., and Jobling, M. 1991. Factors affecting gastric evacuation in cod, Gadus morhua L., fed single-meals of natural prey. Journal of Fish Biology, 38: 697-713.

dos Santos, J., and Jobling, M. 1992. A model to describe gastric evacuation in cod (Gadus morhua L.) fed natural prey. ICES Journal of Marine Science, 49: 145-154.

dos Santos, J., and Jobling, M. 1995. Test of a food consumption model for the Atlantic cod. ICES Journal of Marine Science, 52: 209-219.

Farrell, A. P., Eliason, E. J., Sandblom, E., and Clark, T. D. 2009. Fish cardiorespiratory physiology in an era of climate change. Canadian Journal of Zoology, 87: 835-851.

Jobling, M. 1986. Mythical models of gastric emptying and implications for food consumption studies. Environmental Biology of Fishes, 16: 35-50.

Jones, R. 1974. The rate of elimination of food from the stomachs of haddock Melanogrammus aeglefinus, cod Gadus morhua and whiting Merlangius merlangus. Journal du Conseil International pour l'Exploration de la Mer, 35: 225-243.

Khan, U., Seyhan, K., Basçinar, N., and Basçinar, N. S. 2016. Satiation meal and the effects of meal and body sizes on gastric evacuation rate in brook trout Salvelinus fontinalis fed commercial pellets. Journal of Fish Biology, 89: 1227-1238.

Koed, A. 2001. The effects of meal size, body size and temperature on gastric evacuation in pikeperch. Journal of Fish Biology, 58: 28-290.

Krog, C., and Andersen, N. G. 2009. Are the dynamics of gastric evacuation in a piscivorous flatfish different from what is going on in a gadoid? Journal of Fish Biology, 75: 18311844.

Lannig, G., Bock, C., Sartoris, F. J., and Pörtner, H. O. 2004. Oxygen limitation of thermal tolerance in cod, Gadus morhua L., studied by magnetic resonance imaging and on-line venous oxygen monitoring. American Journal of Physiology, 287: R902-R910.

MacMillan, H. A. 2019. Dissecting cause from consequence: a systematic approach to thermal limits. Journal of Experimental Biology, 222: 1-8.

Ross, S. D., Nielsen, J. R., Gislason, H., Nielsen, A., and Andersen, N. G. 2018. Growth and food consumption of whiting Merlangius merlangus. Journal of Fish Biology, 93: 334343.

Schmidt-Nielsen, K. 1983. Animal Physiology: Adaptation and Environment, 3rd edn. Cambridge University Press, New York, NY, USA 
Salvanes, A. G. V., Aksnes, D. L., and Giske, J. 1995. A surface-dependent gastric evacuation model for fish. Journal of Fish Biology, 47: 679-695.

Sweka, J. A., Cox, M. K., and Hartman, K. J. 2004. Gastric evacuation rates of brook trout. Transactions of the American Fisheries Society, 133: 204-210.

Temming, A., and Andersen, N. G. 1994. Modelling gastric evacuation without meal size as a variable. A model applicable for the estimation of daily ration of cod (Gadus morhua L.) in the field. ICES Journal of Marine Science, 51: 429-438.

Temming, A., and Herrmann, J. -P. 2003. Gastric evacuation in cod. Prey-specific evacuation rates for use in North Sea, Baltic Sea and Baltic Sea multi-species models. Fisheries Research, 63: 21-41. 


\section{Appendix S2}

\section{Estimation of $C_{\mathrm{MAX}}, S_{\max }$ and factorial hyperphagic scope}

\section{Estimation of $C_{\text {MAX from }} S_{\text {MAX }}$}

Here, we derive the episodic assimilative capacity $C_{\mathrm{MAX}}\left(\mathrm{kJ} \mathrm{d}^{-1}\right)$ from field data on maximum stomach content mass $S_{\text {MAX }}(\mathrm{g})$ including assumption about the diel feeding pattern and knowledge about the prey energy density.

If $\tau$ is the (equidistant) time (h) between discrete feeding events where the stomach content mass is replenished to $S_{\mathrm{MAX}}$, then according to the cylinder model the mass $S_{\tau}$ immediately before refilling of the stomach is

$$
S_{\tau}=\left(\sqrt{S_{\mathrm{MAX}}}-\frac{1}{2} \rho \tau\right)^{2} \quad(\mathrm{~g})
$$

where $\rho$ is the rate parameter (Figure S2.1).

Given the prey energy density $E\left(\mathrm{~kJ} \mathrm{~g}^{-1}\right), C_{\mathrm{MAX}}$ is quantified by

$$
\begin{aligned}
C_{\mathrm{MAX}} & =\frac{24 E}{\tau}\left(S_{\mathrm{MAX}}-S_{\tau}\right)=\frac{24 E}{\tau}\left(S_{\mathrm{MAX}}-\left[\sqrt{S_{\mathrm{MAX}}}-\frac{1}{2} \rho \tau\right]^{2}\right) \\
& =24 \rho E\left(\sqrt{S_{\text {MAX }}}-\frac{\rho \tau}{4}\right)=24 \rho E \sqrt{S_{\mathrm{MAX}}}\left(1-\frac{\rho \tau}{4 \sqrt{S_{\mathrm{MAX}}}}\right) \quad\left(\mathrm{kJ} \mathrm{d}^{-1}\right)
\end{aligned}
$$

In one extreme scenario, we assume that the predator does not feed during the following $24 \mathrm{~h}$; i.e., $\tau=24$ in Equation (S2.2). At the other extreme, we assume that the predator is feeding continuously, which implies that $S_{\mathrm{MAX}}$ is maintained throughout [and $\tau \rightarrow 0$ in Equation $(\mathrm{S} 2.2)]$ and

$$
C_{\mathrm{MAX}}=24 \rho E \sqrt{S_{\mathrm{MAX}}} \quad\left(\mathrm{kJ} \mathrm{d}^{-1}\right)
$$

Predatory fish are typically not continuous feeders, so scenarios with one or a few feeding periods a day are the more realistic ones. However, Equation (S2.3) expresses the absolute maximum of daily consumption rate.

\section{Estimation of $S_{\max }$ from $C_{\max }$}

To estimate the prevalence of demonstrated hyperphagia among the sampled fish, we need to derive the maximum stomach content mass $S_{\max }$ from the sustained food consumption rate $C_{\max }$ obtained in long-term laboratory experiments. We use the same feeding scenarios as used for calculation of $C_{\text {MAX }}$ from $S_{\text {MAX. }}$. Thus replacing the subscript 'MAX' by 'max' and reorganizing Equation (S2.2) lead to

$$
S_{\max }=\left(\frac{C_{\max }}{24 \rho E}+\frac{\rho \tau}{4}\right)^{2} \quad(\mathrm{~g})
$$


Similarly, reorganization of Equation $(\mathrm{S} 2.3)$ produces

$$
S_{\max }=\left(\frac{C_{\max }}{24 \rho E}\right)^{2} \quad(\mathrm{~g})
$$

in the case of continuous feeding.

To quantify the sustained food consumption rate $C_{\max }$ for our two predator species we apply the relationships obtained in two long-term laboratory studies:

Using laboratory data on Atlantic cod (Gadus morhua) fed to satiation with capelin (Mallotus villosus) by Johnsen (1981) and Braaten (1984), Jobling (1988) established the relationship

$$
C_{\max }=0.223 W^{0.802} \exp \left(0.104 T-0.000112 T^{3}\right) \quad\left(\mathrm{kJ} \mathrm{d}^{-1}\right)
$$

where $W$ is body mass $(\mathrm{g})$ and $T$ temperature $\left({ }^{\circ} \mathrm{C}\right)$. Assuming isometric growth of cod, $C_{\max }$ scales with $L^{2.41}$.

Similarly, Andersen and Riis-Vestergaard (2003) fed lesser sandeel (Ammodytes tobianus) to whiting (Merlangius merlangus) and obtained the following expression:

$$
C_{\max }=0.0074 L^{2.28} \exp (0.076 T) \quad\left(\mathrm{kJ} \mathrm{d}^{-1}\right)
$$

where $L$ is total body length $(\mathrm{cm})$ and $T$ temperature $\left({ }^{\circ} \mathrm{C}\right)$. Assuming isometric growth of whiting, $C_{\max }$ scales with $W^{0.76}$

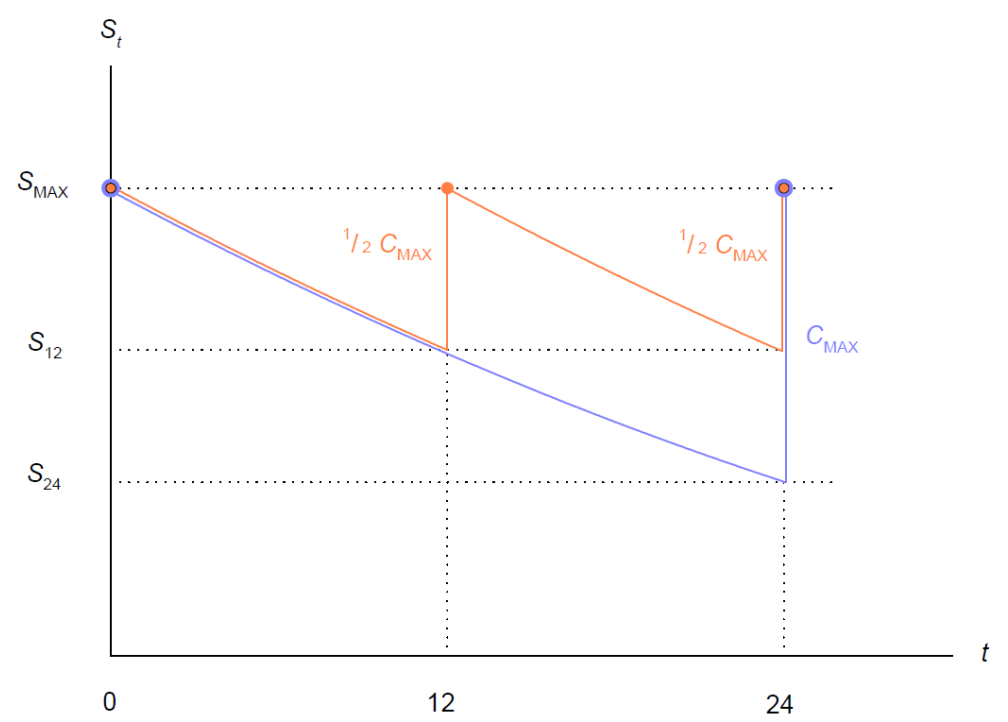

Figure S2.1. The relationship between maximum stomach content mass $S_{\mathrm{MAX}}(\mathrm{g})$ and maximum daily energy intake $C_{\mathrm{MAX}}\left(\mathrm{kJ} \mathrm{d}^{-1}\right)$, where energy density $E\left(\mathrm{~kJ} \mathrm{~g}^{-1}\right)$ for simplicity is put to 1 . Two scenarios: the predator is feeding once (blue) or twice (red) a day (vertical parts of the curves) to replace evacuated food and regain $S_{\mathrm{MAX}}$ (blue and red symbols). Reduction of the current content due to gastric evacuation is described by $S_{t}=\left(\sqrt{S_{\mathrm{MAX}}}-\frac{1}{2} \rho t\right)^{2}$ during total periods $\tau$ of $24 \mathrm{~h}$ and $12 \mathrm{~h}$. 


\section{Factorial hyperphagic scope}

We calculate the factorial hyperphagic scope $C_{\mathrm{MAX}} C_{\max }^{-1}$. In addition to the effect of body size, the estimate of $C_{\mathrm{MAX}}$ depends on temperature and prey energy density [Equation (S1.1)], and $C_{\max }$ on temperature [Equations (S2.6) and (S2.7)]. For cod in the Barents Sea, the scope is calculated at the average values of predator temperature and prey energy density (Figure 4) as well as for values representing their normal ranges (prey energy density, Andersen and Beyer, 2008; temperature, Righton et al., 2010) (Table S2.1). Use of the different variable values does not substantially change the estimates of the scope. This can be explained by the similar effects of temperature on $C_{\max }$ and $C_{\mathrm{MAX}}$ in the relevant temperature interval and by gastric evacuation rate expressed in energy units being almost independent of prey energy density according to the power value -0.85 of $E$ [Equation (S1.1)].

Table S2.1. The factorial hyperphagic scope of $20 \mathrm{~cm}$ and $80 \mathrm{~cm}$ Atlantic cod (Gadus morhua) calculated for nine temperature and prey energy density combinations. The grey bar shows the scenario of average temperature and energy density, whereas the other variable combinations represent their normal ranges.

\begin{tabular}{|c|c|c|c|c|c|}
\hline \multirow{3}{*}{$\begin{array}{c}\text { Temperature } \\
\left({ }^{\circ} \mathrm{C}\right)\end{array}$} & \multirow{3}{*}{$\begin{array}{l}\text { Prey energy } \\
\quad\left(\mathrm{kJ} \mathrm{g}^{-1}\right)\end{array}$} & \multicolumn{4}{|c|}{ Factorial scope of hyperphagia $C_{\mathrm{MAX}} C_{\max }^{-1}$} \\
\hline & & \multicolumn{2}{|c|}{ Feeding once a day or less } & \multicolumn{2}{|c|}{ Continuous feeding } \\
\hline & & $20 \mathrm{~cm}$ & $80 \mathrm{~cm}$ & $20 \mathrm{~cm}$ & $80 \mathrm{~cm}$ \\
\hline 2 & 4 & 1.47 & 2.76 & 1.57 & 2.91 \\
\hline 2 & 6 & 1.59 & 2.98 & 1.67 & 3.09 \\
\hline 2 & 8 & 1.68 & 3.14 & 1.75 & 3.23 \\
\hline 6.4 & 4 & 1.32 & 2.49 & 1.46 & 2.70 \\
\hline 6.4 & 6 & 1.45 & 2.71 & 1.55 & 2.86 \\
\hline 6.4 & 8 & 1.53 & 2.87 & 1.62 & 2.99 \\
\hline 10 & 4 & 1.27 & 2.41 & 1.45 & 2.69 \\
\hline 10 & 6 & 1.41 & 2.65 & 1.54 & 2.85 \\
\hline 10 & 8 & 1.50 & 2.81 & 1.61 & 2.98 \\
\hline
\end{tabular}

A similar insensitivity of the factorial scope to temperature and prey energy density applied to whiting.

Table S2.2. The factorial hyperphagic scope of $20 \mathrm{~cm}$ and $40 \mathrm{~cm}$ whiting (Merlangius merlangus) calculated for six temperature and prey energy density combinations. The grey bar shows the scenario of average temperature at sampling together with the average prey energy density at large for whiting, whereas the other variable combinations represent their normal ranges.

\begin{tabular}{|c|c|c|c|c|c|}
\hline \multirow{3}{*}{$\begin{array}{l}\text { Temperature } \\
\left({ }^{\circ} \mathrm{C}\right)\end{array}$} & \multirow{3}{*}{$\begin{array}{l}\text { Prey energy } \\
\qquad\left(\mathrm{kJ} \mathrm{g}^{-1}\right)\end{array}$} & \multicolumn{4}{|c|}{ Factorial scope of hyperphagia $C_{\mathrm{MAX}} C_{\max }^{-1}$} \\
\hline & & \multicolumn{2}{|c|}{ Feeding once a day or less } & \multicolumn{2}{|c|}{ Continuous feeding } \\
\hline & & $20 \mathrm{~cm}$ & $40 \mathrm{~cm}$ & $20 \mathrm{~cm}$ & $40 \mathrm{~cm}$ \\
\hline 6 & 4 & 1.20 & 1.80 & 1.32 & 1.95 \\
\hline 6 & 6 & 1.31 & 1.96 & 1.40 & 2.08 \\
\hline 6 & 8 & 1.39 & 2.07 & 1.46 & 2.17 \\
\hline 11.7 & 4 & 1.15 & 1.74 & 1.34 & 1.99 \\
\hline 11.7 & 6 & 1.28 & 1.92 & 1.42 & 2.11 \\
\hline 11.7 & 8 & 1.37 & 2.05 & 1.48 & 2.20 \\
\hline
\end{tabular}


Here, we use the average water temperature $11.7^{\circ} \mathrm{C}$ at the stomach sampling stations (sampling was performed in September in two consecutive years) combined with values of prey energy density representing the normal range in the North Sea (Andersen and Beyer, 2008). The temperature at sampling represents the normal upper value for whiting in the

North Sea. Therefore, we also use the normal lower value of $6{ }^{\circ} \mathrm{C}$ (Hislop et al., 1991) combined with the different prey energy values (Table S2.2).

\section{References}

Andersen, N. G., and Riis-Vestergaard, J. 2003. The effects of food consumption rate, body size and temperature on net food conversion efficiency in saithe and whiting. Journal of Fish Biology, 62: 395-412.

Andersen, N. G., and Beyer, J. E. 2008. Predicting ingestion times of individual prey from information about stomach contents of predatory fishes in the field. Fisheries Research, 92: $1-10$.

Braaten, B. 1984. Growth of cod in relation to fish size and ration level. Flodevigen Rapportserie, 1: 677-710.

Hislop, J. R. G., Robb, A. P., Bell, M. A., and Armstrong, D. W. 1991. The diet and food consumption of whiting (Merlangius merlangus) in the North Sea. ICES Journal of Marine Science, 48: 139-156.

Jobling, M. 1988. A Review of the Physiological and Nutritional Energetics of Cod, Gadus morhua L., with Particular Reference to Growth under Farmed Conditions. Aquaculture, 70: $1-19$.

Johnsen, T. 1981. Otolittsoner og vekstprosesser hos torsk (Gadus morhua L.) i Balsfjorden. MSc thesis, University of Troms $\varnothing$

Righton, D. A., Andersen, K. H., Neat, F., Thorsteinsson, V., Steingrund, P., Svedäng, H., Michalsen, K. et al. 2010. Thermal niche of Atlantic cod Gadus morhua: limits, tolerance and optima. Marine Ecology Progress Series, 420: 1-13. 


\section{Appendix S3}

\section{Description of stomach content data and estimation of maximum stomach content mass $S_{\text {MAX }}$ and its allometry}

\section{Stomach content data}

The three datasets on total mass $S$ (g) of contents in individual stomachs described below are available in the accompanying Excel files. For simplification, we only include predatory fish from the body length of $20 \mathrm{~cm}$ onwards for which fish prey dominate the diet in all three datasets.

\section{Atlantic cod (Gadus morhua) sampled in the Barents Sea}

The dataset is described by Holt et al. (2019). The data have been sampled annually since 1984 with good seasonal coverage except for the second quarter of the year. Only the Norwegian data from this joint Norwegian-Russian dataset are available for the current study $(n=153970)$ and include approximately half the total dataset. Sampling is mainly carried out during scientific bottom trawl surveys, and it covers the entire size range from $4 \mathrm{~cm}$ and up to a total body length of $146 \mathrm{~cm}$, although there are few samples of cod outside the range 10$100 \mathrm{~cm}$. The temperature experienced by cod in the Barents Sea ranges from $-1{ }^{\circ} \mathrm{C}$ to $10{ }^{\circ} \mathrm{C}$ (Ottersen et al., 1998; Righton et al., 2010; Fall et al., 2018). However results from individual cod with data storage tags suggest that Arctic cod generally avoid temperatures below $2{ }^{\circ} \mathrm{C}$ (Righton et al., 2010; Thorsteinsson et al., 2012), which is corroborated by the strong negative effect of lower temperatures on gastric evacuation rate in the cod (Salvanes et $a l .$, 1995). The stomachs were analysed individually for prey composition and the individual prey items weighed. Capelin (Mallotus villosus) is the most important fish prey, representing about $30 \%$ of total stomach content mass of $20-80 \mathrm{~cm} \operatorname{cod}(n=121917$ out of which 40 outliers with stomach content mass far above $25 \%$ body mass were excluded). We truncated the dataset at $80 \mathrm{~cm}$ because of low number of fish by 1-cm group above this size. Liver mass data are primarily available from $40-80 \mathrm{~cm} \operatorname{cod}\left(n=36718\right.$ out of which 3 outliers with $I_{\mathrm{HS}}$ far above $35 \%$ were excluded).

\section{Whiting (Merlangius merlangus) sampled in the North Sea}

The dataset is described by Rindorf (2002). The whiting were caught by bottom trawling at five locations in the North Sea in early September 1988 and 1989. In total, stomachs from 8300 whiting ranging from $14 \mathrm{~cm}$ to $47 \mathrm{~cm}$ were collected out of which 7526 (20-47 cm fish) were used in our analyses. The stomachs were analysed individually for prey composition and the individual prey items weighed. The prey were assigned to species (fishes) or major taxa (invertebrates). The average temperature at the stations was $11.7^{\circ} \mathrm{C}$. Sandeel (Ammodytidae), clupeids and Norway pout (Trisopterus esmarkii) constitute the vast majority of prey mass in the stomachs of fish $\geq 20 \mathrm{~cm}$ in the North Sea (Hislop et al., 1991).

\section{Whiting (Merlangius merlangus) sampled in the western Baltic Sea}

The dataset is described by Ross et al. (2016). The whiting were caught during quarterly bottom trawl surveys from May 2011 to August 2013 at a number of fixed stations according to the design applied in the Baltic International Trawl Survey (BITS) and the extended 
Fehmarn Belt Survey. The stations covered spatially and temporally the habitat of whiting in the western Baltic Sea. The contents of the collected stomachs $(n=2347)$ from whiting of body lengths between 5 and $53 \mathrm{~cm}$ were therefore assumed to reflect the diet and stomach content mass of whiting in the area. The quarterly average temperatures experienced by the whiting ranged from $4{ }^{\circ} \mathrm{C}$ to $13{ }^{\circ} \mathrm{C}$. The stomachs were analysed individually for prey composition and the individual prey items weighed. Clupeids constitute the vast majority of prey mass in stomachs $(n=1469)$ of fish $\geq 20 \mathrm{~cm}$.

\section{Maximum stomach content mass $S_{\text {MAX }}$ and its allometry}

For the body length range $20-80 \mathrm{~cm} L(n=121877)$ of the large dataset on cod, we calculated the $99.9^{\text {th }}$ percentiles of $S$ by 1-cm class of $L$ to represent the size-specific maximum mass of stomach content $S_{\text {MAX }}(\mathrm{g})$. Nonlinear regression of the power function $S_{\text {MAX }}=\kappa_{\text {MAX }} L^{b}$ provided a value of the exponent $b$ close to the isometric relationship of 3 (Table S3.1). Fixing $b$ at 3 , the prefactor $\kappa_{\text {MAX }}$ was then estimated alone. Using lower percentiles (for example the $97.5^{\text {th }}$ and $99.0^{\text {th }}$ did not significantly affect the estimate of $b$ pointing to the robustness of this large dataset.

The number of observations in the two smaller dataset on whiting did not allow for split into $1-\mathrm{cm} L$ classes, so all data on $S$ were normalized to $L=1 \mathrm{~cm}$ by $\kappa=S L^{-3}$ and the obtained values of $\kappa$ were used to obtain $\kappa_{\text {MAX }}$ by the $99.9^{\text {th }}$ percentile. Data on $20+\mathrm{cm}$ whiting from the North Sea $(n=7526)$ were grouped into three $L$ classes $(20-24,25-29,>29 \mathrm{~cm})$ providing three values of $\kappa_{\text {MAX }}$ to obtain an estimate with confidence limits. Data on $20+\mathrm{cm}$ whiting from the small dataset in the western Baltic Sea $(n=1469)$ did not allow for calculation of more than one value (Table S3.1).

Table S3.1. Estimates of the parameters in the relationship $S_{\mathrm{MAX}}=\kappa_{\mathrm{MAX}} L^{b}$ between total body length $L(\mathrm{~cm})$ and maximum mass of total stomach content $S_{\text {MAX }}(\mathrm{g})$. Values of $\kappa_{\text {MAX }}$ with different superscripts letter are significantly different $(t$-test, $\mathrm{P}<0.05)$.

\begin{tabular}{|c|c|c|c|c|c|c|}
\hline \multirow[b]{2}{*}{ Predator population } & \multirow[b]{2}{*}{$L$ range } & \multicolumn{2}{|c|}{$\kappa_{\operatorname{MAX}}\left(\times 10^{-3}\right)$} & \multicolumn{2}{|c|}{$b$} & \multirow[b]{2}{*}{$n *$} \\
\hline & & Estimate & $95 \% \mathrm{CI}$ & Estimate & $95 \% \mathrm{CI}$ & \\
\hline \multicolumn{7}{|l|}{ Atlantic cod (Gadus morhua) } \\
\hline The Barents Sea & $20-80$ & $\begin{array}{l}1.47 \\
1.72^{\mathrm{a}}\end{array}$ & $\begin{array}{l} \pm 0.48 \\
\pm 0.06\end{array}$ & $\begin{array}{c}3.04 \\
3\end{array}$ & $\begin{array}{l} \pm 0.08 \\
\text { (fixed) }\end{array}$ & 61 \\
\hline \multicolumn{7}{|c|}{ Whiting (Merlangius merlangus) } \\
\hline The North Sea & $20-47$ & $1.26^{\mathrm{b}}$ & \pm 0.14 & 3 & (fixed) & 3 \\
\hline The western Baltic Sea & $20-53$ & 1.32 & & 3 & - & 1 \\
\hline
\end{tabular}

*Number of calculated $99.9^{\text {th }}$ percentiles

The isometric relationship between $S_{\mathrm{MAX}}$ and $L$ obtained here is in accord with the relationship between the stomach mass itself and $L$ in Appendix S1. It is furthermore generally substantiated in a number of field studies as well as in laboratory studies on artificially induced maximum inflation of the stomach (e.g., Flowerdew and Grove, 1979; Pope et al., 2001). 


\section{References}

Fall, J., Ciannelli, L., Skaret, G., and Johannesen, E. 2018. Seasonal dynamics of spatial distributions and overlap between Northeast Arctic cod (Gadus morhua) and capelin (Mallotus villosus) in the Barents Sea. PLOS ONE, 13, e0205921. https://doi.org/10.1371/journal.pone.0205921

Flowerdew, M. W., and Grove, D. J. 1979. Some observations of the effects of body weight, temperature, meal size and quality on gastric emptying time in the turbot, Scophthalmus maximus (L.) using radiography. Journal of Fish Biology, 14: 229-238.

Hislop, J. R. G., Robb, A. P., Bell, M. A., and Armstrong D. W. 1991. The diet and food consumption of whiting (Merlangius merlangus) in the North Sea. ICES Journal of Marine Science, 48: 139-156.

Holt, R. E., Bogstad, B., Durant, J. M., Dolgov, A. V., and Ottersen, G. 2019. Barents Sea cod (Gadus morhua) diet composition: long-term interannual, seasonal, and ontogenetic patterns. ICES Journal of Marine Science, 76: 1641-1652.

Ottersen, G., Michalsen, K., and Nakken, O. 1998. Ambient temperature and distribution of north-east Arctic cod. ICES Journal of Marine Science, 55: 67-85.

Pope, K. L., Brown, M. L., Duffy, W. G., and Michaletz, P. H. 2001. A caloric-based evaluation of diet indices for largemouth bass. Environmental Biology of Fishes, 6: 329339.

Righton, D. A., Andersen, K. H., Neat, F., Thorsteinsson, V., Steingrund, P., Svedäng, H., Michalsen, K. et al. 2010. Thermal niche of Atlantic cod Gadus morhua: limits, tolerance and optima. Marine Ecology Progress Series, 420: 1-13.

Rindorf, A. 2002. The effect of stomach fullness on food intake of whiting in the North Sea. Journal of Fish Biology, 61: 579-593.

Ross, S. D., Gislason, H., Andersen, N. G., Lewy, P., and Nielsen, J. R. 2016. The diet of whiting Merlangius merlangus in the western Baltic Sea. Journal of Fish Biology, 88: 1965-1988.

Salvanes, A. G. V., Aksnes, D. L., and Giske, J. 1995. A surface-dependent gastric evacuation model for fish. Journal of Fish Biology, 47: 679-695.

Thorsteinsson, V., Pálsson, O. K., Tómasson, G. G., Jónsdóttir, I. G., and Pampoulie, C. 2012. Consistency in the behaviour types of the Atlantic cod: repeatability, timing of migration and geo-location. Marine Ecology Progress Series, 462: 251-260. 


\section{Appendix S4}

\section{Maximum food consumption rate and stomach filling of well-fed and pre- starved Atlantic cod (Gadus morhua) in laboratory experiments}

Using the results from two explorative laboratory experiments described below, we show here that the level of maximum stomach filling depends on the nutritional status of cod. In particular, the results corroborate that the maximum mass of stomach content $S_{\mathrm{MAX}}$ estimated from cod stomachs sampled in the Barents Sea corresponds quite well to the hyperphagic response $C_{\mathrm{MAX}}$ to poor nutritional condition of the fish.

In a bioenergetics study, Andersen and Riis Vestergaard (2003) estimated the sustained maximum food consumption rate $C_{\max }$ from feeding experiments on groups of saithe (Pollachius virens) and whiting (Merlangius merlangus). First, they wanted to examine whether the experimental set-up provides reliable estimates of $C_{\max }$, but no prior information on these species was available. Therefore, they performed an explorative experiment with a group of well-nourished cod fed satiation meals of lesser sandeel (Ammodytes tobianus) once a day to compare the results with those of Jobling (1988) parameterized in Equation (S2.6). Second, to examine the effects of nutritional status on consumption rate and compensatory growth, they conducted a pilot experiment on another group of cod starved for 8 weeks prior to the experiment (allowed only a sub-maintenance ration once a week). Due to multiple problems with the water supply, the latter experiment was terminated long before intended, and the consumption rate appeared rather variable. The results from the latter experiment were therefore never published. However, they can be used to gain some insight into the dynamics of $C_{\mathrm{MAX}}$ vs $C_{\max }$ and $S_{\mathrm{MAX}}$ vs $S_{\max }$ for cod.

Here, we compare the daily average per capita food consumption rates of the well-fed cod to Jobling's $C_{\max }$ calculated from Equation (S2.6) (Figure 5a). Those of the pre-starved fish were similarly compared to $C_{\mathrm{MAX}}$ of the Barents Sea cod population obtained from the maximum mass of sampled stomach content $S_{\mathrm{MAX}}$ using the cylinder model of gastric evacuation rate (GER) [Equation (S2.2) with $\tau=24 \mathrm{~h}$ : one feeding event per day; prey energy density of $\left.6 \mathrm{~kJ} \mathrm{~g}^{-1}\right]$.

Using the GER model, we further estimate the stomach filling of the pre-starved cod in the successive days of the experiment from the daily average per capita consumption rates. This is compared to the maximum mass of stomach content $S_{\mathrm{MAX}}$ obtained from the Barents Sea cod population (Figure 5b). The current stomach filling $S_{n}(\mathrm{~g})$ of the pre-starved cod immediately after feeding on day $n$ is calculated as a the result of the prey mass remaining from the preceding day plus the consumption of the new meal $C_{n}(\mathrm{~kJ})$ :

$$
S_{n}=\left(\sqrt{S_{n-1}}-\frac{1}{2} \rho 24\right)^{2}+C_{n} E^{-1}
$$

where $S_{n-1}(\mathrm{~g})$ is the prey mass immediately after feeding the preceding day, $\rho\left(\sqrt{\mathrm{g}} \mathrm{h}^{-1}\right)$ the rate parameter of the GER model for sandeel prey, and $E\left(\mathrm{~kJ} \mathrm{~g}^{-1}\right)$ the prey energy density. At day 0 , the first term at the right side of the equation attains the value of 0 . We applied the same procedure to the feeding rates $C_{n}$ of the well-fed cod. Their daily stomach filling was compared to $S_{\max }$ (corresponding to Jobling's $C_{\max }$ ) using Equation (S2.4) with $\tau=24 \mathrm{~h}$ (one feeding event per day). 
We calculated the curves that describe $C_{\mathrm{MAX}}, C_{\max }, S_{\mathrm{MAX}}$, and $S_{\max }$ in Figure 5 by body size considering that fish is growing linearly in length during the experiment. Body mass by day used for $C_{\max }$ was estimated assuming isometric growth and applying Fulton's condition factor of the well-fed fish. The basic data of the experiments are compiled in Table S4.1. Details of acquisition and acclimation of fish as well as conduction of experiments are similar to those described in Andersen and Riis-Vestergaard (2003).

Table S4.1. Basic data (mean \pm s.d.) of two feeding experiments on well-fed and pre-starved cod fed sandeel prey of $6.0 \mathrm{~kJ} \mathrm{~g}^{-1}$ to satiation once a day at $10.1^{\circ} \mathrm{C}$. Duration of the experiments appears from Figure 5.

\begin{tabular}{|c|c|c|c|c|c|c|c|c|}
\hline \multirow[b]{2}{*}{ Experiment } & \multicolumn{4}{|c|}{ Start } & \multicolumn{4}{|c|}{ End } \\
\hline & $\begin{array}{l}\text { Length } \\
(\mathrm{cm})\end{array}$ & $\begin{array}{l}\text { Mass } \\
(\mathrm{g})\end{array}$ & $* K$ & $\begin{array}{c}\text { Fish } \\
(n)\end{array}$ & $\begin{array}{l}\text { Length } \\
(\mathrm{cm})\end{array}$ & $\begin{array}{l}\text { Weight } \\
\text { (g) }\end{array}$ & $* K$ & $\begin{array}{c}\text { Fish } \\
(n)\end{array}$ \\
\hline Well-fed & $27.2 \pm 1.5$ & $218 \pm 40$ & $1.07 \pm 0.06$ & 75 & $30.1 \pm 1.6$ & $299 \pm 52$ & $1.09 \pm 0.08$ & 74 \\
\hline Pre-starved & $30.7 \pm 1.4$ & $212 \pm 36$ & $0.73 \pm 0.05$ & 37 & $32.6 \pm 1.7$ & $309 \pm 55$ & $0.88 \pm 0.06$ & 37 \\
\hline
\end{tabular}

* Fulton's condition factor $K=100 W L^{-3}$, where $L$ is total length $(\mathrm{cm})$ and $W$ is body mass $(\mathrm{g})$

The daily food intake was variable for both groups of cod (Figure 5a). After the first two days on restricted food rations, the well-fed fish consumed a large meal to fill the stomach. The same applied to the pre-starved fish after three days of restricted food rations (as a precautious measure to avoid a sudden nutritional overload after prolonged starvation). Thus, the initial maximum food intakes represent a transition, and it cannot be compared to the calculated curves of $C_{\max }$ and $C_{\mathrm{MAX}}$.

At each feeding, the fish seemed to replenish the amount of stomach content to a relatively constant level that differed significantly between the two groups (Figure $5 \mathrm{~b}$ ). Whereas that of the well-fed fish corresponds well to the level expected for fish feeding according to $C_{\max }$ (Jobling 1988), the pre-starved fish filled their stomachs to a level close to $S_{\text {MAX }}$ estimated from the Barents Sea population. This corroborates the assumption that $S_{\text {MAX }}$ represent a hyperphagic response to poor nutritional condition of the fish, when the prey availability allows for binge feeding. Accordingly, the factorial scope of hyperphagia amounted to 1.63 for the prey-starved laboratory fish, which is close to the value of 1.71 obtained for cod of similar size from the Barents Sea population.

The duration of hyperphagia depends on how quickly the reserves are replenished to the targeted level, which depends on the actual nutritional state, the amount of ingested energy and the strategy of allocation to reserves and structural growth (Jobling and Johansen, 1999; Gurney et al., 2003). The pre-starved cod maintained hyperphagia for all 10 days of feeding to satiation, and Fulton's condition factor increased from 0.73 to 0.88 , whereas that of the well-fed fish displaying sustained maximum consumption rates was relatively constant at 1.07-1.09 (Table S4.1). Assuming that a condition factor of 1.08 represents the targeted reserve level, the displayed hyperphagia of the pre-starved fish would be of substantially longer duration had the experiment not been terminated prematurely. 
For comparison, the mean value of Fulton's condition factor for the sampled Barents Sea cod of $27-32 \mathrm{~cm}(n=9932)$ was 0.84 with lower and upper $95 \%$ confidence limits of 0.65 and 1.02. Extrapolating the experimental results to the Barents Sea population, most of these cod should display hyperphagia, when the opportunity arises.

\section{References}

Andersen, N. G. and Riis-Vestergaard, J. 2003. The effects of food consumption rate, body size and temperature on net food conversion efficiency in saithe and whiting. Journal of Fish Biology, 62: 395-412.

Gurney, W. S. C., Jones, W., Veitch, A. R., and Nisbet, R. M. 2003. Resource Allocation, Hyperphagia, and Compensatory Growth in Juveniles. Ecology, 84: 2777-2787.

Jobling, M. 1988. A Review of the Physiological and Nutritional Energetics of Cod, Gadus morhua L., with Particular Reference to Growth under Farmed Conditions. Aquaculture, 70: $1-19$.

Jobling, M. and Johansen, S. J. S. 1999. The lipostat, hyperphagia and catch-up growth. Aquaculture Research, 30: 473-478. 